\title{
Inhibition of sphingosine-1-phosphate phosphatase 1 promotes cancer cells migration in gastric cancer: Clinical implications
}

\author{
XIANG Y. GAO ${ }^{1,2}$, LIN LI $^{1}$, XIAO H. WANG ${ }^{1}$, XIAN Z. WEN ${ }^{1}, \mathrm{KE} \mathrm{JI}^{2}$, \\ LIN YE ${ }^{2}$, JUN CAI ${ }^{2}$, WEN G. JIANG ${ }^{2}$ and JIA F. JI ${ }^{1}$ \\ ${ }^{1}$ Beijing Cancer Hospital and Key Laboratory of Carcinogenesis and Translational Research, \\ Department of Gastrointestinal Surgery, Peking University Cancer Hospital and Institute, Beijing 100142, P.R. China; \\ ${ }^{2}$ Cardiff China Medical Research Collaborative, Cardiff University School of Medicine, Heath Park, Cardiff CF14 4XN, UK
}

Received March 11, 2015; Accepted April 9, 2015

DOI: $10.3892 /$ or.2015.4162

\begin{abstract}
Sphingosine-1-phosphate (S1P) plays an important role in regulating many biological processes. Sphingosine-1-phosphate phosphatase 1 (SGPPl) can dephosphorylate S1P into sphingosine and tip the balance of sphingosine-S1P. Increased levels of sphingosine leads to a decrease in the ability of cell invasion as well as an increase in the ability of cell apoptosis. However, little is known regarding the effects of SGPPl in gastric cancer. The present study examined the function of SGPPl on gastric cancer cell lines as well as its clinical relevance in gastric cancer progression. Using immunohistochemistry and RT-qPCR techniques, the clinical significance of SGPPl expression was analyzed in 288 paraffin-embedded gastric tissue specimens and 219 fresh gastric tissues, respectively. Transgenes encoding ribozymes to specifically target human SGPPI (pEF-SGPPI) was constructed. Human gastric cancer cell lines (AGS and HGC27) were transfected with pEF-SGPPl transgene and examined by functional analysis. SGPPI was downregulated in gastric cancer tissues, compared with adjacent normal gastric tissues $(\mathrm{p}=0.034)$. SGPPl mRNA levels in gastric cancer tissues were significantly decreased when compared with their adjacent non-cancerous tissues $(\mathrm{p}<0.001)$. Weakly expressed $S G P P 1$ was positively correlated with the lymph node metastasis $(\mathrm{p}=0.005)$ and distant metastasis $(\mathrm{p}=0.031)$. Kaplan-Meier survival curves revealed that patients with
\end{abstract}

Correspondence to: Professor Jia F. Ji, Beijing Cancer Hospital and Key Laboratory of Carcinogenesis and Translational Research, Department of Gastrointestinal Surgery, Peking University Cancer Hospital and Institute, 52 Fu-Cheng Road, Beijing 100142, P.R. China E-mail: jiafuj@hotmail.com

Professor Wen G. Jiang, Cardiff China Medical Research Collaborative, School of Medicine, Cardiff University, Heath Park, Cardiff CF14 4XN, UK

E-mail: jiangw@cardiff.ac.uk

Key words: sphingosine-1-phosphate phosphatase 1, SGPP1, gastric cancer, migration, invasion
SGPP1 positive expression had a significant increase in overall survival $(\mathrm{OS})(\mathrm{p}=0.034)$ and progression-free survival (PFS) $(\mathrm{p}=0.041)$. Multivariate analysis indicated the expression of SGPPI was an independent prognostic factor in gastric cancer patients $(\mathrm{p}=0.041)$. In vitro experiments showed that knockdown of SGPPI resulted in an increase in the invasion (2-fold) and migration (5-fold) of AGS and HGC27. The two gastric cancer cells transfected with pEF-SGPPI exhibited a slower rate of growth with less adhesion. Thus, our findings provided evidence that SGPPI may serve as a prognostic biomarker for patients with advanced gastric cancers.

\section{Introduction}

Gastric cancer is the fifth most common cancer and the third leading cause of cancer mortality worldwide (1). Surgery alone is no longer acceptable as a standard treatment for resectable gastric cancer (2). Optimal locoregional treatment for gastric cancer can be achieved by a combination of radical surgery with individualized neoadjuvant or adjuvant treatment, with modern 3D radiotherapy and optimum target therapy (3). Many clinical trials showed that although chemotherapy and target therapy are effective in short-term treatment for advanced gastric cancer (4-6), these treatments do not improve overall survival (OS) rate ( $<1$ year). Thus, sensitive validated biomarkers for early detection of the tumor and a more accurate prediction of disease outcome as well as patient response to treatments can significantly improve efficacy of the treatments and greatly decrease the mortality of gastric cancer.

Sphingosine-1-phosphate $(S 1 P)$ has been identified to play an important regulatory role in proliferation, inflammation, vasculogenesis and anti-apoptosis (7). Sphingosine-1-phosphate phosphatase 1 (SGPP1), which is intracellularly localized on endoplasmic reticulum (ER), is responsible for converting SIP to sphingosine (8). SGPP1 is located in the region $14 \mathrm{q} 23.2$ of the chromosome (9). Furthermore, overexpression of SGPP1 may elevate ceramide levels and induce apoptosis, whereas knockdown of SGPPl enhanced resistance to TNF- $\alpha$, the chemotherapeutic agent daunorubicin (8) and radiotherapy (10).

In the present study, we aimed to examine the possible role of SGPP1 in the progression of gastric cancer and determine whether SGPP1 may serve as a prognostic biomarker. 


\section{Materials and methods}

Materials. Human gastric cancer cell lines, AGS and HGC27 were obtained from the European Collection of Cell Cultures, (ECACC; Salisbury, UK). Reagents and kits were obtained from Promega Corporation (Madison, WI, USA) and Gibco Invitrogen Corporation (Paisley, Scotland, UK). Anti-SGPPI antibody (Santa Cruz Biotechnology, Inc., Santa Cruz, CA, USA), TRI reagent (Sigma-Aldrich, Poole, UK), Universal Z Probe (TCS Biologicals Ltd., Oxford, UK), and the DC Protein Assay kit (Bio-Rad, Hemel Hempstead, UK) were also used in the present study.

Gastric tissues. Gastric adenocarcinoma or Siewert type III gastroesophageal junction (GEJ) adenocarcinoma tissues (282 of paraffin-embedded tissues and 218 of fresh-frozen tissues), along with matched normal tissue from the same patients, were collected immediately after surgical resection at the Beijing Cancer Hospital and were stored in the Tissue Bank of Peking University Oncology School. Clinicopathological factors, including age, gender, histological type, Lauren type, tumor location, vascular invasion, TNM stage and lymph node metastasis, were recorded and stored in the patients' database. All protocols were reviewed and approved by the Local Ethics Committee. Informed consent was obtained from the patients before therapy.

The gastric tissues used in the present study were obtained from gastric cancer patients with cT2-4N0M0 or cT1-4N1-3M0 treated between January, 2003 and December, 2011. Gastrectomy with D2 lymphadenectomy was performed and no treatment was conducted before the surgery. Primary tumor site, grade, depth of tumor invasion, status of lymph node metastasis, distant metastasis and TNM stage were recorded in histopathology reports. Pathological stage was determined according to the seventh edition of the TNM staging system recommended by the International Union against Cancer.

Immunohistochemistry (IHC). Sections (4 mm) obtained from formalin-fixed, paraffin-embedded tissues were mounted on poly-L-lysine-coated slides and then deparaffinised in xylene and rehydrated through alcohol to distilled water. Endogenous peroxidase activity was blocked with $3 \%$ hydrogen peroxide for $15 \mathrm{~min}$ at room temperature. After pressure cooking the slides in $10 \mathrm{mmol} / \mathrm{l}$ EDTA (pH 8.0) for $3 \mathrm{~min}$, the sections were incubated with 5\% goat serum, then incubated overnight at $4^{\circ} \mathrm{C}$ with $S G P P 1$ antibody (1:200; Santa Cruz Biotechnology, Inc.) and without the primary antibody as a negative control. Primary antibodies were detected using a two-step EnVision system (Dako, Glostrup, Denmark). Horseradish peroxidase and diaminobenzedene hydrochloride were the enzyme and chromogen used, respectively. Staining score was independently assessed by two pathologists. The percentage of positive cells and the intensity of cytoplasmic staining were analyzed. Thus all final scoring estimations were stratified as follows: ,$- 0 \%$ of stained cells;,$+<20 \%$ weakly to moderately stained cells; ++, $10-20 \%$ intensively stained cells and $20-50 \%$ weakly stained cells; and +++, 20-50\% positive cells with moderate-tomarked staining or $>50 \%$ positive cells. There was a low level of discrepancy ( $<5 \%$ cases) among the pathologists in terms of scoring, but a consensus was reached after joint review.
$R N A$ isolation and RT-PCR. Total RNA was isolated from the homogenized gastric tissues and cell lines using the Total RNA Isolation reagent (TRI reagent; Sigma-Aldrich). Synthesis of cDNA and subsequent PCR were performed as previously described (11). SGPP1 primers used were: sense, 5'-GGGCAACGAACTCTTCTAC-3' and antisense, 5'-TCC AGGTGTCAAGAGTGAA-3'.

Quantitative RT-PCR. The level of SGPPI transcripts was quantitatively analyzed with the iCycler iQ5 system with qPCR Master Mix (both from Bio-Rad) as previously described (12). SGPPl primers designed using the Beacon Design software (Premier Biosoft, Palo Alto, CA, USA) were as follows: sense, 5'-ATGGACAAGCATCCCTTCC-3' and antisense, 5'-ACTGAACCTGACCGTACACTCTGTCAGGG AAATACCAA3-3'. The underlined sequence in the reverse primers was the additional $\mathrm{Z}$ sequence, which is complementary to the Universal Z Probe (TCS Biologicals Ltd. , Oxford, UK). Internal standard GAPDH primer sequences used were: sense, 5'-CTGAGTACGTCGTGGAGTCC-3' and antisense, 5'-ACTGAACCTGACCGTACAGAGATGATGACCCTT TTG-3'. To exclude the effect of tissue heterogeneity, the SGPP1 quantification was normalized against the corresponding CK19 (an epithelial marker) of each individual sample. The primers used for CK19 were: sense, 5'-CAGGTC CGAGGTTACTGAC-3' and antisense, 5'-ACTGAACCTGAC CGTACACCGTTTCTGCCAGTGTGTCTTC-3'.

Construction of SGPP1 ribozyme transgenes and transfection. Anti-SGPP1 ribozyme transgenes were used to knock down the expression of SGPPI in the AGS and HGC27 gastric cancer cells and were generated using the methods previously described (13). Briefly, an anti-SGPPI hammerhead ribozyme was designed based on the secondary structure of SGPPI mRNA and generated using the Zuker's RNA mFold program. The ribozymes that specifically target DAP3 were generated using the touchdown PCR with the appropriate primers (sense, 5'-CTGCAGTTCAACCACTTCTCCCAGAGCTGATGAGT CCGTGAGGA-3' and antisense, 5'-ACTAGTAGAGAAAGC ACTGAGAAAGGGAGTTTCGTCCTCACGGACT-3'). The amplified ribozymes were cloned into the pEF6/V5-His TOPO TA plasmid vector (Invitrogen, Paisley, UK) in accordance with the protocol provided. Ribozyme transgenes and control plasmids were transfected into HGC27 and AGS cells individually using an Easyjet Plus electroporator (EquiBio, Kent, UK). After up to 5 days of selection with blasticidin, the transfectants were verified for knockdown of SGPPI.

Western blotting. HGC27 and AGS cells were plated into small flasks at a density of $25 \times 10^{5}$ cells/well. Proteins were isolated from cells by lysis buffer. Protein concentrations were determined using the DC Protein Assay kit (Bio-Rad) and an ELx800 spectrophotometer (Bio-Tek, Bedfordshire, UK). Western blot analysis was performed after SDS-PAGE and transferred onto membranes. The proteins were probed with the anti-SGPPI-antibody (1:500) and anti-GAPDH-antibody $(1: 1,000)$ (Santa-Cruz Biotechnology, Inc.) as an internal control, followed by a peroxidase-conjugated secondary antibody $(1: 1,000)$. Protein bands were visualized and photographed using a UVITech imager (UVITech, Inc., Cambridge, UK). 
Table I. Association of SGPP1 expression with clinicopathological characteristics in gastric cancer patients.

\begin{tabular}{|c|c|c|c|}
\hline \multirow[b]{2}{*}{$\begin{array}{l}\text { Clinicopathological } \\
\text { characteristics }\end{array}$} & \multicolumn{2}{|c|}{ SGPP1 expression } & \multirow[b]{2}{*}{ P-value } \\
\hline & $\begin{array}{l}\text { Negative } \\
(\%)\end{array}$ & $\begin{array}{l}\text { Positive } \\
(\%)\end{array}$ & \\
\hline Gender & & & 0.357 \\
\hline Male & $138(71.1)$ & $56(28.9)$ & \\
\hline Female & $65(76.5)$ & $20(23.5)$ & \\
\hline Age (years) & & & 0.616 \\
\hline$\leq 60$ & $100(71.4)$ & $40(28.6)$ & \\
\hline$>60$ & $103(74.1)$ & $36(25.9)$ & \\
\hline Tumor location & & & 0.016 \\
\hline Upper $1 / 3$ & $37(61.7)$ & $23(38.3)$ & \\
\hline Middle 1/3 & $45(67.2)$ & $22(32.8)$ & \\
\hline Low $1 / 3$ & $112(78.3)$ & $31(21.7)$ & \\
\hline Total & $9(100.0)$ & $0(0.0)$ & \\
\hline Cardia and non-cardia & & & 0.007 \\
\hline Non-cardiac cancer & $175(76.1)$ & $55(23.9)$ & \\
\hline Cardiac cancer & $28(57.1)$ & $21(42.9)$ & \\
\hline Tumor size (cm) & & & 0.855 \\
\hline$\leq 4.0$ & $112(73.2)$ & $41(26.8)$ & \\
\hline$>4.0$ & $91(72.2)$ & $35(27.8)$ & \\
\hline Lauren type & & & 0.560 \\
\hline Intestinal type & $40(70.2)$ & $17(29.8)$ & \\
\hline Diffuse & $116(75.3)$ & $38(24.7)$ & \\
\hline Mixed type & $47(69.1)$ & $21(30.9)$ & \\
\hline Differentiation & & & 0.216 \\
\hline Well-moderate & $90(69.2)$ & $40(30.8)$ & \\
\hline Poor & $113(75.8)$ & $36(24.2)$ & \\
\hline Well & $7(58.3)$ & $5(41.7)$ & 0.474 \\
\hline Moderate & $83(70.3)$ & $35(29.7)$ & \\
\hline Poor & $101(76.5)$ & $31(23.5)$ & \\
\hline Signet & $12(70.6)$ & $5(29.4)$ & \\
\hline Histology & & & 0.464 \\
\hline Adenocarcinoma & $169(71.9)$ & $66(28.1)$ & \\
\hline Other types ${ }^{\mathrm{a}}$ & $34(77.3)$ & $10(22.7)$ & \\
\hline Lymphovascular invasion & & & 0.486 \\
\hline Absent & $100(70.9)$ & $41(29.1)$ & \\
\hline Present & $103(74.6)$ & $35(25.4)$ & \\
\hline \multicolumn{4}{|l|}{ Depth of invasion } \\
\hline $\mathrm{T}_{1}$ & $14(77.8)$ & $4(22.2)$ & 0.385 \\
\hline $\mathrm{T}_{2}$ & $25(67.6)$ & $12(32.4)$ & \\
\hline $\mathrm{T}_{3}$ & $7(100.0)$ & $0(0.0)$ & \\
\hline $\mathrm{T}_{4}$ & $157(72.4)$ & $60(27.6)$ & \\
\hline $\mathrm{T}_{1}+\mathrm{T}_{2}$ & $39(42.5)$ & $16(57.5)$ & 0.731 \\
\hline $\mathrm{T}_{3}+\mathrm{T}_{4}$ & $164(26.0)$ & $60(74.0)$ & \\
\hline $\mathrm{T}_{1}$ & $14(77.8)$ & $4(22.2)$ & 0.787 \\
\hline $\mathrm{T}_{2}+\mathrm{T}_{3}+\mathrm{T}_{4}$ & $189(72.4)$ & $72(27.6)$ & \\
\hline \multicolumn{4}{|l|}{ Lymph node metastasis } \\
\hline $\mathrm{N}_{0}$ & $46(71.9)$ & $18(28.1)$ & 0.005 \\
\hline $\mathrm{N}_{1}$ & $28(53.8)$ & $24(46.2)$ & \\
\hline $\mathrm{N}_{2}$ & $35(76.1)$ & $11(23.9)$ & \\
\hline $\mathrm{N}_{3}$ & $94(80.3)$ & $23(19.7)$ & \\
\hline No & $46(71.9)$ & $18(28.1)$ & 0.856 \\
\hline Yes & $157(73.0)$ & $58(27.0)$ & \\
\hline
\end{tabular}

Table I. Continued. Association of SGPP1 expression with clinicopathological features in gastric cancer patients.

\begin{tabular}{lccc}
\hline & \multicolumn{2}{c}{ SGPP1 expression } & \\
\cline { 2 - 3 } Clinicopathological & $\begin{array}{c}\text { Negative } \\
\text { features }\end{array}$ & $\begin{array}{c}\text { Positive } \\
(\%)\end{array}$ & \\
\hline Distant metastasis & & & P-value \\
No & $177(70.8)$ & $73(29.2)$ & 0.031 \\
Yes & $26(89.7)$ & $3(10.3)$ & \\
TNM stage & & & 0.171 \\
I & $26(74.3)$ & $9(25.7)$ & \\
II & $28(68.3)$ & $13(31.7)$ & \\
III & $123(70.7)$ & $51(29.3)$ & \\
IV & $26(89.7)$ & $3(10.3)$ & \\
I & $26(74.3)$ & $9(25.7)$ & 0.828 \\
II-IV & $177(72.5)$ & $67(27.5)$ & \\
I+II & $54(71.1)$ & $22(28.9)$ & 0.695 \\
III+IV & $149(73.4)$ & $54(26.6)$ & \\
\hline
\end{tabular}

${ }^{a}$ Other types: Signet-ring cell carcinoma and mucinous adenocarcinoma. SGPP1, sphingosine-1-phosphate phosphatase 1.

Cell growth assay. Crystal violet assay was conducted as previously described (11). Cells were added into 96-well plates at $2 \times 10^{3}$ cells/well. The cells were fixed in $4 \%$ paraformaldehyde at room temperature for 10 min after 1, 3 and 5 days. After being washed, the plates were stained with $0.5 \%$ crystal violet solution. The plates were washed with tap water and air-dried. Acetic acid (10\%) was added to each well for extraction of dye. Growth rates under normal conditions and under treatment were assessed. Absorbance of the staining was determined by a spectrophotometer at $540 \mathrm{~nm}$ (ELx800; Bio-Tek).

Cell matrix adhesion assay. The cell matrix adhesion assay was performed as previously described (14). Cells were added to a 96-well plate precoated with Matrigel $(5 \mathrm{mg} /$ well) ( $2 \times 10^{4}$ cells/well). After $40 \mathrm{~min}$ of incubation, non-adherent cells were washed off using BSS buffer. The remaining cells were fixed with $4 \%$ paraformaldehyde, stained with $0.5 \%$ crystal violet solution and counted.

Wound-healing assay. The motility of gastric cancer cells was analyzed using a wound-healing assay as previously described (15). The cells were grown until they reached confluence. A scrape in the cell monolayer was made in one direction with a fine gauge needle. The wounded cell monolayers were washed with PBS to remove cell debris. The migration of the invading cell front was recorded on a time lapse video recorder and analyzed using Optimas 6.0 motion analysis (Meyer Instruments, Houston, TX, USA).

Invasion assay. The in vitro Matrigel invasion assay was performed as previously described (15). Transwell inserts with $8-\mathrm{mm}$ pore size were coated with $50 \mu \mathrm{g}$ of Matrigel (Collaborative Research Products, Bedford, MA, USA) and air-dried. Following rehydration, $4 \times 10^{4}$ cells were added 

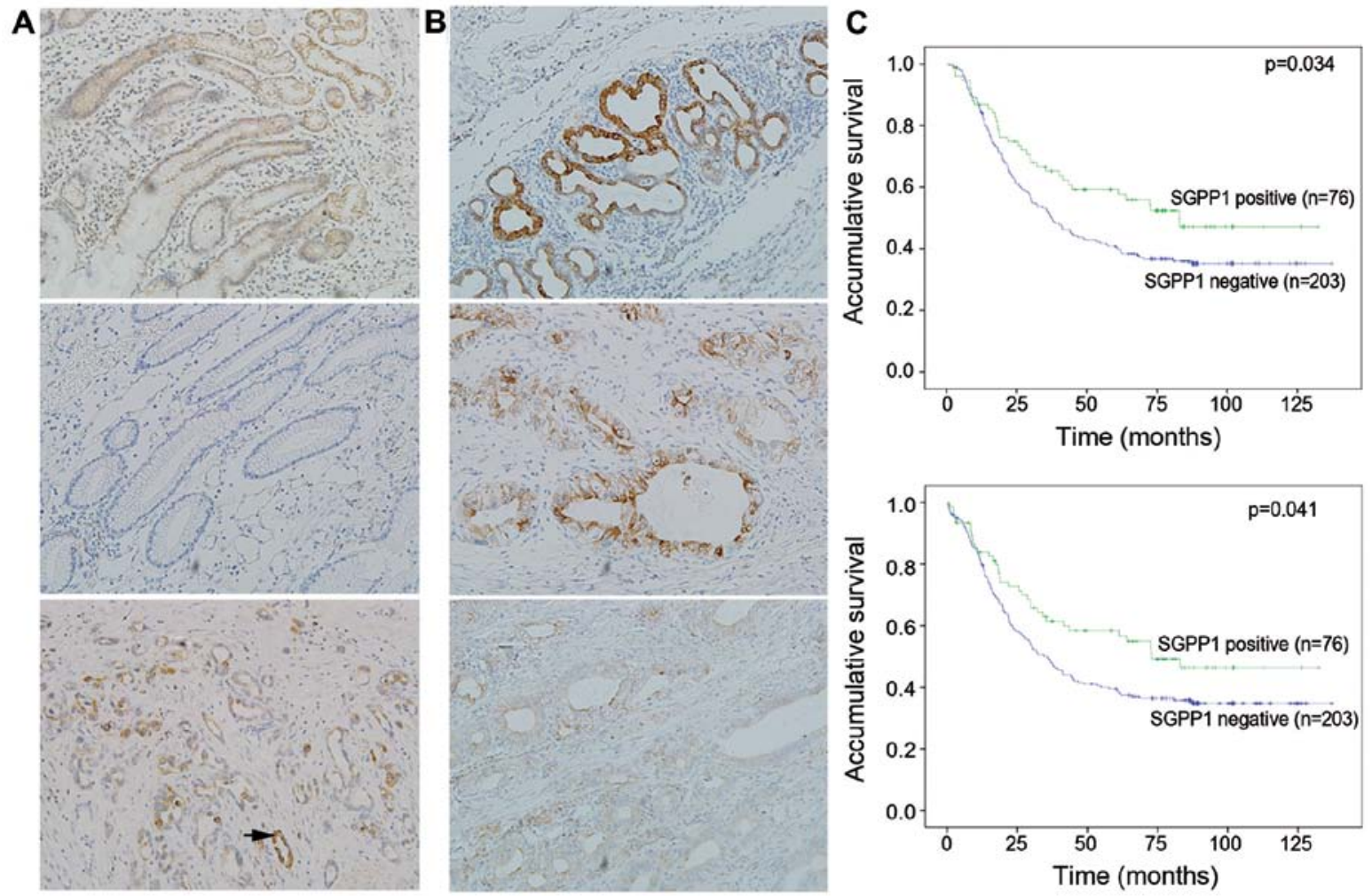

Figure 1. (A) Representative images of immunohistochemical staining of SGPP1 on gastric tissues including the positive control (top panel), the negative control (middle panel) and the location of cytoplasm (bottom panel, with arrow pointing to the staining of SGPP1 in the cytoplasm of cancer cells). (B) Representative images of immunohistochemical staining of SGPP1 on gastric tumor tissues including the strong (top panel), moderate (middle panel) and weak (bottom panel) expression. (C) Kaplan-Meier survival analysis indicated that the relationship between the protein levels of SGPPI and overall survival (top) and the relationship between the protein levels of SGPP1 and progression-free survival (bottom). SGPP1, sphingosine-1-phosphate phosphatase 1.

to each well. After 3 days of incubation, the cells that had migrated through the matrix to the other side of the insert were fixed, stained and counted.

Statistical analysis. Statistical analysis was performed using the SPSS software (SPSS standard version 13.0; SPSS Inc.). The relationship between $S G P P 1$ expression and tumor grade, TNM staging and nodal status was assessed using the Mann-Whitney U test and Kruskal-Wallis test. Survival was analyzed using the Kaplan-Meier survival analysis. Results are presented as mean \pm SEM. $\mathrm{P}<0.05$ was considered statistically significant.

\section{Results}

Immunohistochemical staining of SGPPl in human gastric specimens.In total,282 paraffin-embedded specimens of gastric cancer patients from Beijing Cancer Hospital were included in the IHC study. This cohort comprised 196 males (69.5\%) and 86 females $(31.5 \%)$, with a median age of 69 (22-87) years. The patients underwent surgery without any prio treatment. The median follow-up time was 41.13 (1.00-137.17) months. The result was that, 36 patients had recurrence, 130 patients succumbed to gastric cancer, 15 patients succumbed to other causes (heart attack and cerebral haemorrhage), 11 were lost in follow-up and 107 remained alive and progression-free.

Negative staining results were considered as low expression and '+', '++', '+++' as high expression. SGPPl was mainly detected in cytoplasm and the staining was obviously stronger in normal tissue compared with tumor tissues $(\mathrm{p}<0.001)$. A low expression of $S G P P 1$ was positively associated with lymph node metastasis $(\mathrm{p}=0.005)$ and distant metastasis $(\mathrm{p}=0.031)$ (Table I). Kaplan-Meier survival curves revealed that patients with a high SGPP1 expression had a significant increase in OS and progression-free survival (PFS) in gastric cancer patients $(\mathrm{p}=0.034,0.041$; Fig. 1). Multivariate analysis indicated the expression of SGPPl was an independent prognostic factor in gastric cancer patients $(\mathrm{p}=0.041$; Table II).

Quantification of SGPPI mRNA expression in human gastric cancer. mRNA derived from the 219 gastric cancer patient tissues from the Beijing Cancer Hospital were subjected to a SGPPl gene-specific qPCR study. This cohort comprised 144 males $(65.8 \%)$ and 75 females $(34.2 \%)$. The patients underwent the surgery without any prior treatment. The result was that, 86 patients were alive, 130 patients succumbed to gastric cancer, 9 patients had metastasis and 117 remained disease-free.

We compared the transcript levels of SGPPl in gastric cancer tissues with adjacent normal tissues of patients. The transcript level of SGPPI was significantly different in the $\mathrm{T}$ stage $(\mathrm{p}=0.009)$ and TNM stage $(\mathrm{p}=0.0255)$. Statistical analysis revealed significant links between the different clinical outcomes $(\mathrm{p}=0.0379)$ and different transcript levels. A markedly decreased transcript of SGPPl was observed in tumor tissues compared with the normal background tissues ( $\mathrm{p}<0.0001$; Table III). 
Table II. Patient survival associated with clinicopathological characteristics in gastric cancer.

\begin{tabular}{|c|c|c|c|c|c|c|}
\hline \multirow{2}{*}{$\begin{array}{l}\text { Clinicopathological } \\
\text { characteristics }\end{array}$} & \multicolumn{3}{|c|}{ Univariate analysis } & \multicolumn{3}{|c|}{ Multivariate analysis } \\
\hline & RR & $95 \% \mathrm{CI}$ & P-value & $\mathrm{RR}$ & $95 \% \mathrm{CI}$ & P-value \\
\hline \multicolumn{7}{|l|}{ Gender } \\
\hline Male vs. female & 1.211 & $0.858-1.710$ & 0.276 & & & \\
\hline \multicolumn{7}{|l|}{ Age (years) } \\
\hline$\leq 60$ vs. $>60$ & 0.787 & $0.579-1.068$ & 0.125 & & & \\
\hline \multicolumn{7}{|l|}{ Tumor location } \\
\hline Upper $1 / 3$ & 0.380 & $0.184-0.784$ & 0.009 & & & \\
\hline Middle $1 / 3$ & 0.212 & $0.101-0.446$ & 0.230 & & & \\
\hline Low $1 / 3$ & 0.257 & $0.128-0.514$ & 0.118 & & & \\
\hline Multiple site & 0.000 & & & & & \\
\hline \multicolumn{7}{|l|}{ Tumor size $(\mathrm{cm})$} \\
\hline$>4.0$ vs. $\leq 4.0$ & 0.661 & $0.487-0.897$ & 0.008 & & & \\
\hline \multicolumn{7}{|l|}{ Lauren type } \\
\hline Intestinal vs. diffuse/mixed & 1.042 & $0.718-1.514$ & 0.828 & & & \\
\hline \multicolumn{7}{|l|}{ Differentiation } \\
\hline Well-moderate vs. poor & 1.270 & $0.935-1.726$ & 0.126 & 1.411 & $1.017-1.957$ & 0.039 \\
\hline \multicolumn{7}{|l|}{ Histology } \\
\hline Adenocarcinoma vs. other types ${ }^{a}$ & 1.264 & $0.851-1.877$ & 0.246 & & & \\
\hline \multicolumn{7}{|l|}{ Lymphovascular invasion } \\
\hline Absent vs. present & 2.072 & $1.519-2.825$ & $<0.001$ & 1.449 & $1.046-2.007$ & 0.026 \\
\hline \multicolumn{7}{|l|}{ Depth of invasion } \\
\hline $\mathrm{T}_{1}$ & 0.000 & & 0.938 & & & \\
\hline $\mathrm{T}_{2}$ & 0.160 & $0.160-0.544$ & 0.000 & & & \\
\hline $\mathrm{T}_{3}$ & 0.153 & $0.153-2.499$ & 0.500 & & & \\
\hline $\mathrm{T}_{4}$ & 1 & & 0.001 & & & \\
\hline $\mathrm{T}_{1}+\mathrm{T}_{2}$ vs. $\mathrm{T}_{3}+\mathrm{T}_{4}$ & 5.375 & $2.911-9.924$ & $<0.001$ & 2.627 & $1.372-5.033$ & 0.004 \\
\hline \multicolumn{7}{|l|}{ Lymph node metastasis } \\
\hline $\mathrm{N}_{0}$ & 0.118 & $0.066-0.211$ & $<0.001$ & & & \\
\hline $\mathrm{N}_{1}$ & 0.241 & $0.148-0.391$ & $<0.001$ & & & \\
\hline $\mathrm{N}_{2}$ & 0.673 & $0.431-0.942$ & 0.024 & & & \\
\hline $\mathrm{N}_{3}$ & 1.000 & & $<0.001$ & & & \\
\hline No vs. yes & 5.391 & $3.055-9.513$ & $<0.001$ & 3.628 & $1.990-6.614$ & $<0.001$ \\
\hline \multicolumn{7}{|l|}{ Distant metastasis } \\
\hline No vs. yes & 0.168 & $0.110-0.256$ & $<0.001$ & 0.277 & $0.179-0.428$ & $<0.001$ \\
\hline \multicolumn{7}{|l|}{ SGPP1 } \\
\hline Negative vs. positive & 0.673 & $0.465-0.973$ & 0.036 & 0.671 & $0.458-0.985$ & 0.041 \\
\hline
\end{tabular}

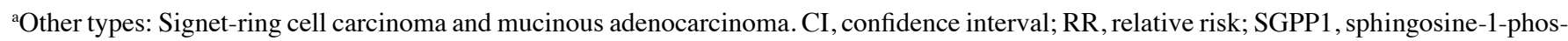
phate phosphatase 1 .

Knockdown effect of SGPPI on the functions of gastric cancer cells. The expression of SGPPI in HGC27 and AGS cells transfected with corresponding anti-SGPP1 ribozyme transgenes was examined using conventional PCR. The results showed a significantly lower expression level of $S G P P I$ compared with the control group (2- to 3-fold) (Fig. 2A), and the same knockdown effect was observed in qPCR and western blot analysis (2- to 3-fold) (Fig. 2B and C).
Migration and invasion assay. To determine whether downregulating the expression of SGPP1 affected the biological behavior of gastric cancer cell lines, we performed a wound-healing assay of the cells. The AGS and HGC27 cells transfected with anti-SGPP1 ribozyme exhibited a significant increase in the ability of migration of tumor cells compared with the control cells. A significant difference was identified for the two cells ( $\mathrm{p}<0.05,2$ - to 5 -fold; Fig. 3A). 
Table III. Correlation of the mRNA expression of SGPP1 and clinical parameters.

\begin{tabular}{|c|c|c|c|c|c|}
\hline Category & No. & Median & Q1 & Q3 & P-value \\
\hline $\mathrm{T} / \mathrm{Nb}$ & & & & & $<0.001$ \\
\hline Normal & 183 & 2.50 & 0 & 56 & \\
\hline Tumor & 322 & 0.10 & 0 & 21 & \\
\hline Gender & & & & & 0.7876 \\
\hline Male & 229 & 0.10 & 0 & 16 & \\
\hline Female & 93 & 0.10 & 0 & 29 & \\
\hline \multicolumn{6}{|l|}{ Location } \\
\hline Cardia & 66 & 0.30 & 0 & 53 & \\
\hline Fundus & 21 & 2.90 & 0 & 52 & 0.3310 \\
\hline Corpus & 61 & 0.10 & 0 & 27 & 0.4796 \\
\hline Pylorus & 130 & 0.00 & 0 & 16 & 0.1696 \\
\hline \multicolumn{6}{|l|}{ Differentiation } \\
\hline Diff-H & 1 & 0.00 & N/A & N/A & \\
\hline Diff-HM & 6 & 0.03 & 0 & 1.69 & \\
\hline Diff-M & 62 & 0.03 & 0 & 6 & 0.3812 \\
\hline Diff-ML & 81 & 0.08 & 0 & 28 & 0.2121 \\
\hline Diff-L & 137 & 0.10 & 0 & 29 & 0.2510 \\
\hline \multicolumn{6}{|l|}{ T stage } \\
\hline $\mathrm{T} 1$ & 16 & 0.01 & 0 & 0.64 & \\
\hline $\mathrm{T} 2$ & 25 & 0.00 & 0 & 0 & 0.3706 \\
\hline $\mathrm{T} 3$ & 31 & 6.20 & 0 & 83 & 0.0586 \\
\hline $\mathrm{T} 4$ & 232 & 0.08 & 0 & 26 & 0.2526 \\
\hline $\mathrm{T} 1+\mathrm{T} 2$ & 41 & 0.00 & 0 & 0 & \\
\hline $\mathrm{T} 3+\mathrm{T} 4$ & 273 & 0.10 & 0 & 28 & \\
\hline \multicolumn{6}{|l|}{$\mathrm{N}$ stage } \\
\hline No & 71 & 0.00 & 0 & 5 & \\
\hline N1 & 48 & 0.00 & 0 & 8 & 0.8221 \\
\hline $\mathrm{N} 2$ & 64 & 0.00 & 0 & 24 & 0.1375 \\
\hline \multirow[t]{2}{*}{ N3 } & 133 & 0.00 & 0 & 45 & 0.0244 \\
\hline & & & 0.00 & & 0.0519 \\
\hline No & 133 & 0.00 & 0 & 45 & \\
\hline $\mathrm{N} 1+\mathrm{N} 2+\mathrm{N} 3$ & 245 & 0.00 & 0 & 29 & \\
\hline M stage & & & 0 & & 0.7139 \\
\hline M0 & 280 & 0.10 & 0 & 13 & \\
\hline M1 & 41 & 0.00 & 0 & 93 & \\
\hline TNM stage & & & 0 & & \\
\hline I & 25 & 0.00 & 0 & 0.60 & \\
\hline II & 59 & 0.02 & 0 & 10 & 0.5474 \\
\hline III & 220 & 0.20 & & 30 & 0.0516 \\
\hline IV & 9 & 1.00 & 0 & 258 & 0.0334 \\
\hline & & & & & 0.0255 \\
\hline I+II & 84 & 0.00 & 0 & 4 & \\
\hline III+IV & 229 & 0.00 & 0 & 32 & \\
\hline Vascular invasion & & & & & 0.6462 \\
\hline No invasion & 152 & 0.00 & 0 & 23 & \\
\hline Invasion & 155 & 0.10 & 0 & 19 & \\
\hline Clinical outcome & & & 0 & & 0.0379 \\
\hline Alive & 134 & 0.00 & 0 & 4 & \\
\hline Dead & 185 & 0.40 & 0 & 45 & \\
\hline
\end{tabular}

SGPP1, sphingosine-1-phosphate phosphatase 1.
The effect of SGPPI knockdown on cell lines on migration was investigated using an in vitro invasion assay. The decrease in the expression of SGPPI was significantly correlated with an increase in cell invasion in AGS and HGC27 cell lines ( $\mathrm{p}<0.05,3$-fold; Fig. 3B).

Adhesion and growth assay. An in vitro matrix adhesion assay was used to investigate the effect of SGPPl knockdown on cell lines on the adhesion ability of gastric cancer cell lines. The HGC27 and AGS cell lines transfected with SGPP1 ribozyme significantly inhibited matrix adhesion ability compared with the control cell line ( $p<0.05$, 2- to 5 -fold; Fig. 4A).

Furthermore, to determine whether the expression of $S G P P 1$ affected the growth of gastric cancer cells, we carried out a growth assay. The results showed that the HGC27 cell line transfected with $S G P P 1$ ribozyme markedly inhibited growth on day $5(\mathrm{p}<0.05)$ and there was no significant difference on day 3 , whereas this effect was not observed in the AGS cell line transfected with $S G P P 1$ ribosome (Fig. 4B).

\section{Discussion}

Gastric cancer has become the fifth most common cancer worldwide over the past decades. There are $\sim 480,000$ new patients developing this cancer in China each year (1). At the same time, gastric cancer, whose estimated mortality rates ranks the highest in China, has also become the third leading cause of cancer mortality worldwide. Although the incidence rates of gastric cancer have gradually decreased (16), $80 \%$ of patients with gastric cancer in China are at an advanced stage (17).

Despite new developments in the treatment for advanced gastric cancer patients, such as adjuvant chemotherapy (18), new adjuvant chemotherapy and concurrent chemoradiotherapy (19) plus surgery or surgery, the 5-year survival rate of patients has only been marginally improved (20). The main reason for this lack of significant improvement is mostly due to the fact that diagnosis is frequently made after progression to later stages, at which point current therapeutic strategies exert limited effectiveness. Furthermore, the major challenge to cancer treatment is the recurrence of diseases due to therapeutic resistance. In many patients, microscopic or macroscopic metastases have already occurred by the time the in situ lesion is detected. Therefore, early detection and more accurate methods in predicting disease outcomes, may enable physicians to make informed decisions regarding the potential necessity of early intervention. Consequently, early intervention would significantly decrease the mortality of gastric cancer and greatly improve the 5-year survival rate.

S1P is a bioactive sphingolipid that is important in regulating diverse biological processes (21). S1P is a component of cell membranes with high amphotericity, which enables S1P to possess sufficient aqueous solubility to move between membranes (22-24) as a bioactive signalling molecule. S1P is known to be involved in the regulation of diverse biological behavior. Particularly, S1P has emerged as an important signalling mediator participating in the regulation of various cell processes and diseases, including cancer, wound healing, atherosclerosis and immunity. S1P functions through either a family of five $G$ protein-coupled membrane receptors known as SIPRI-5 $(25,26)$ or intracellular targets, 


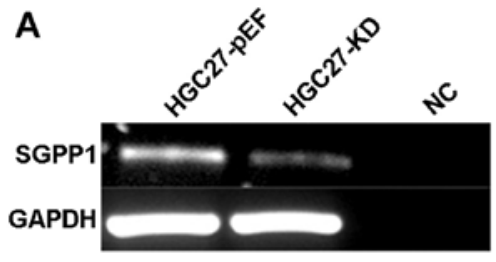

SGPP1 HGC27 KD MRNA
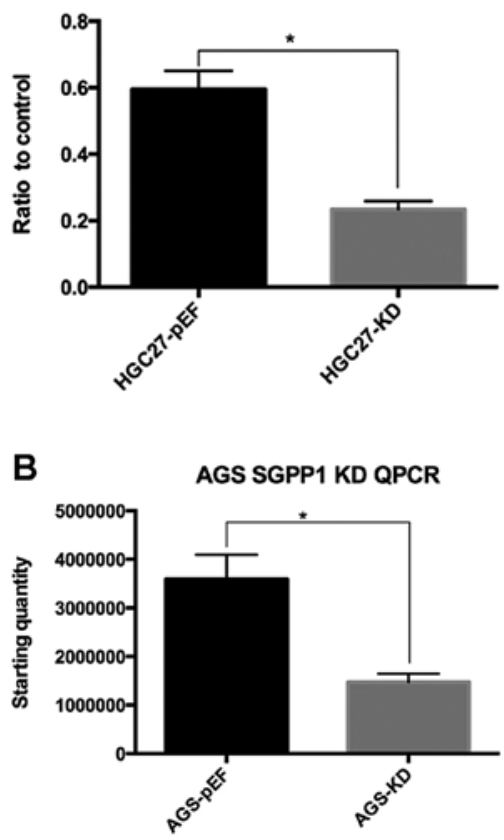

C

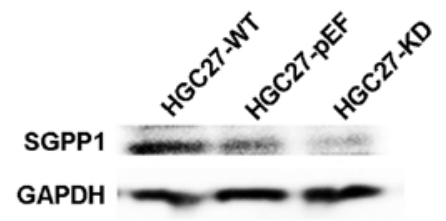

SGPP1 HGC27 KD Protein

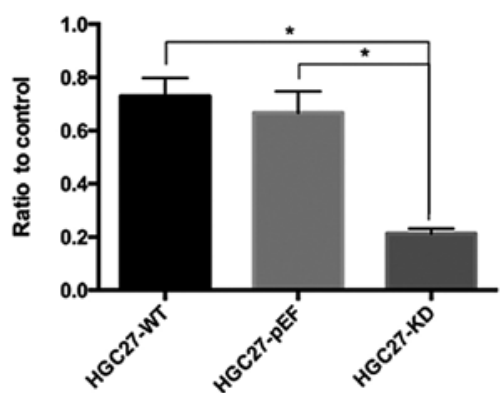

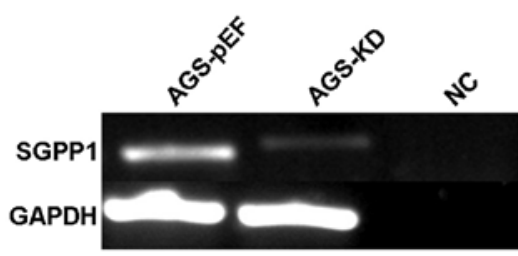

SGPP1 AGS KD MRNA
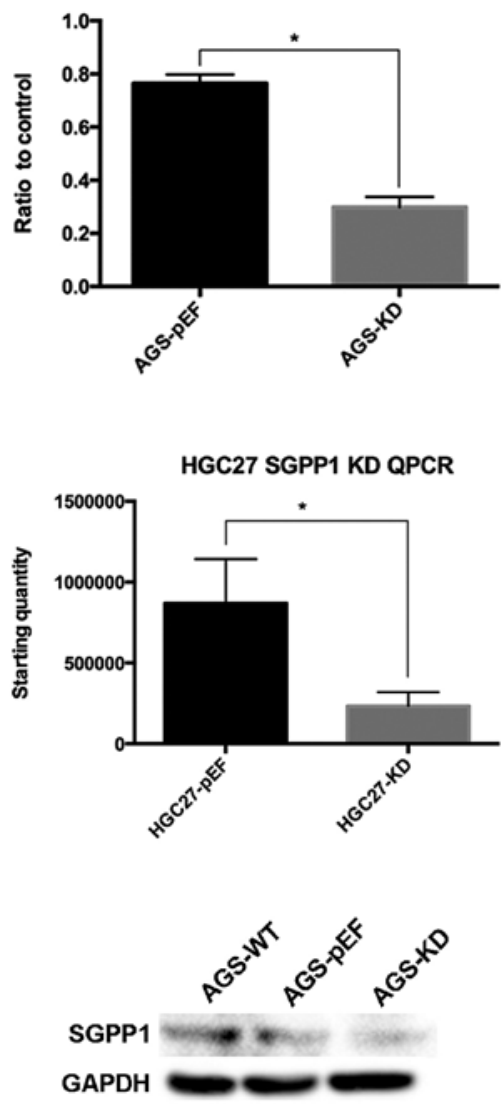

SGPP1 AGS KD Protein

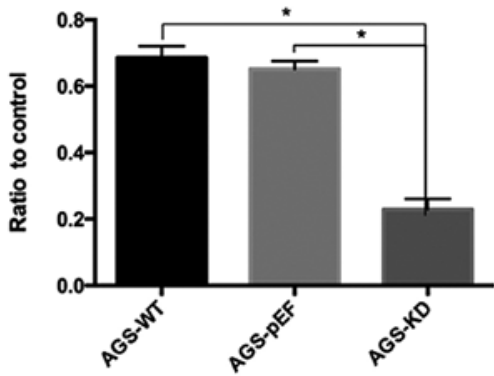

Figure 2. (A) Representative image of RT-PCR analysis of efficacy of SGPP1 knockdown in HGC27 and AGS cells, respectively, with correspondent densitometric analysis [presented as the relative ratio of SGPP1 to GAPDH, $(\mathrm{n}=3)$ ]. (B) RT-qPCR analysis confirmed SGPP1 knockdown in HGF27 and AGS cells, respectively. (C) Western blot analysis of SGPP1 protein levels in HGC27 and AGS cells used in response to SGPP1 knockdown. P<0.05, statistically significant. SGPP1, sphingosine-1-phosphate phosphatase 1.

such as, prohibitin 2 (27), TNF receptor-associated factor 2 (TRAF2) (28), and histone deacetylase (HDAC) (29). Through interaction of these intracellular targets, $\mathrm{S} 1 \mathrm{P}$ regulates a wide variety of biological effects (30), such as cell movement, differentiation, survival, inflammation, immunity, calcium homeostasis, and angiogenesis.

S1P may be dephosphorylated by SGPPS which convert S1P to sphingosine. Previous studies have shown that SIP level has a 2-fold increase in the SGPPs knockdown cell lines (8). There are two isoforms of SGPPs, SGPP1 (31) and SGPP2 (32). $S G P P S$ can dephosphorylate $S 1 P$ to regenerate sphingosine, leading to $S 1 P$ inactivation. This, in turn, would lead cells to apoptosis as well as degeneration (9). SGPPS were highly selective for sphingolipid substrates (33). SGPPs have also been reported to be regulated by other factors. For example, laminar shear stress also downregulates the expression of SGPPl while 

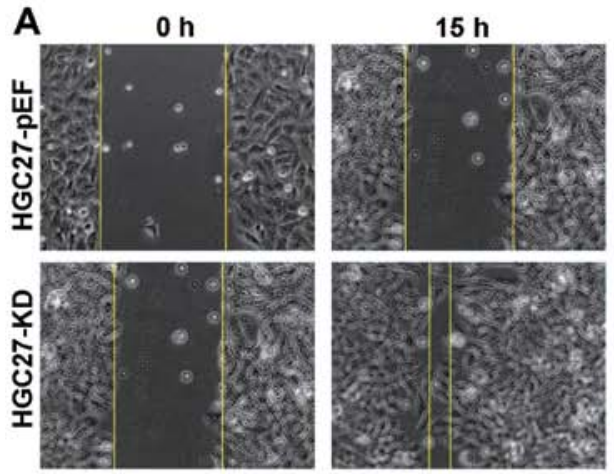

HGC27 SGPP1 wound-healing assay
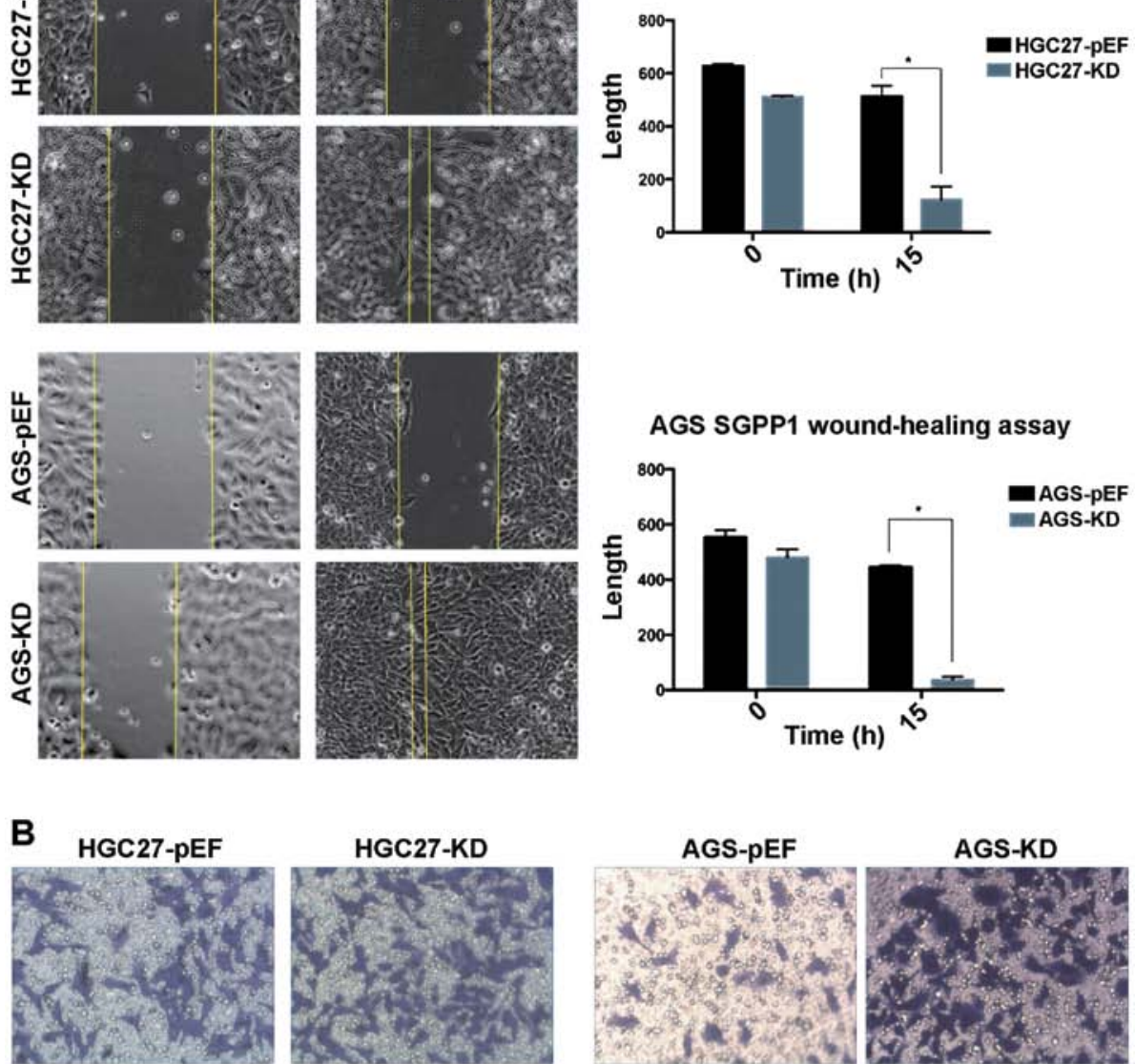

HGC27-KD

AGS-pEF

AGS-KD
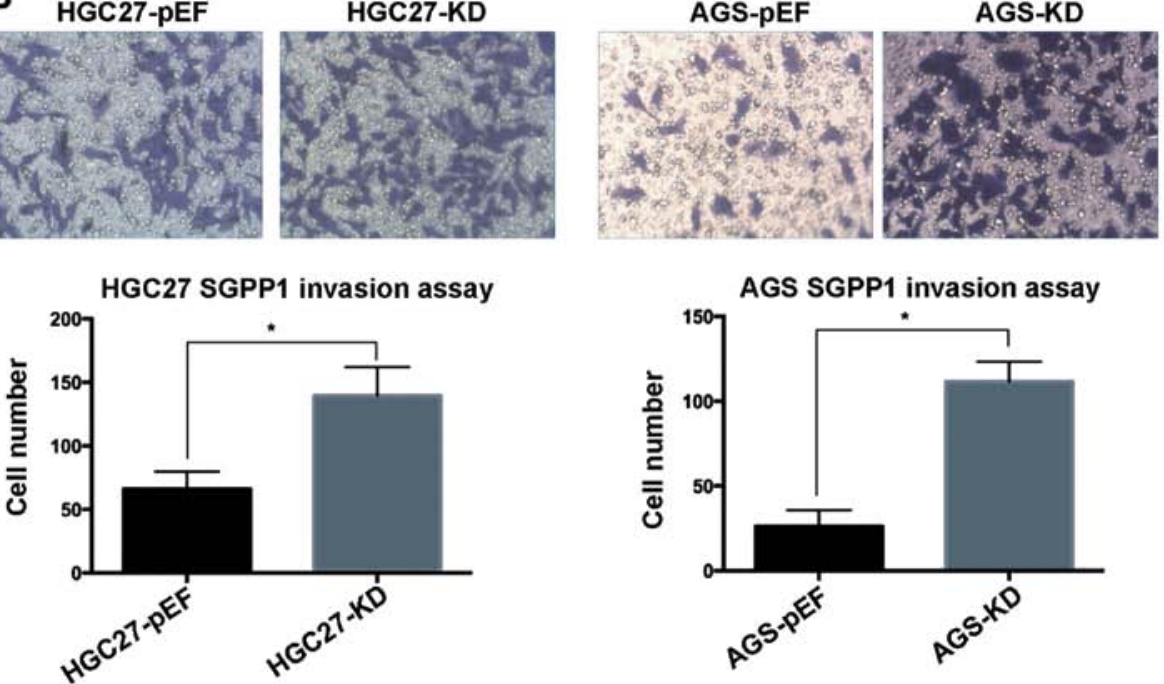

Figure 3. (A) Wound-healing assay was used to assess the effect of $S G P P 1$ knockdown on the migration ability of the gastric cancer cells. HGC27 cells (top panel) and AGS cells (bottom panel). (B) The influence of SGPP1 knockdown on the invasive ability of HGC27/AGS cells. HGC27 cells (left panel) and AGS cells (right panel). Data shown are the mean value of three experiments in triplicate. Experiments were repeated at least three times. Data are presented as mean \pm SEM; ${ }^{*}$ p $<0.05$. SGPP1, sphingosine-1-phosphate phosphatase 1 .

concomitantly stimulating $S 1 P$ released from endothelial cells in vitro (34). SGPP1 may also control the unfolded protein response and ER stress-induced autophagy (35), as well as vascular tone (36). Overexpression of SGPPS may elevate ceramide levels and provoke apoptosis, whereas knockdown of SGPPl enhanced resistance to TNF- $\alpha$ and the chemotherapeutic agent daunorubicin (8) and radiotherapy (10) (Fig. 5).

In this study, we examined the function of SGPPl on gastric cancer cell lines as well as its clinical significance in gastric cancer progression. SGPPI is a potential biomarker candidate for early diagnosis and/or prognosis for patients with advanced gastric cancer. By accessing a relative large cohort of gastric cancer, we retrospectively evaluated the relationship between the level of SGPPI expression and clinical characteristics. Our results showed that the patients who had a higher level of $S G P P 1$ expression had a longer OS and PFS compared with a lower level of SGPPI expression. Our study has demonstrated that a positive expression of SGPPl was an early diagnosis of improved clinical outcome in gastric cancer patients. In addition, the study showed that $S G P P 1$ expression was statistically associated with the location of tumor and lymph node metastasis in gastric cancer patients. Moreover, multivariate survival analysis showed that $S G P P 1$ was an independent prognostic factor. Based on these results, we suggest that $S G P P I$ was a 


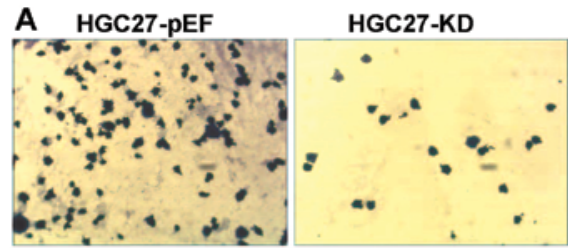

HGC27 SGPP1 adhesion assay

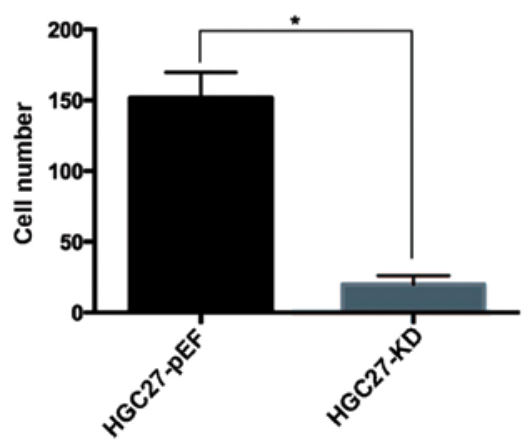

B

SGPP1 HGC27 growth assay

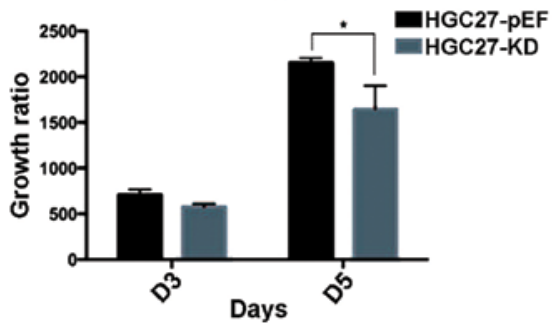

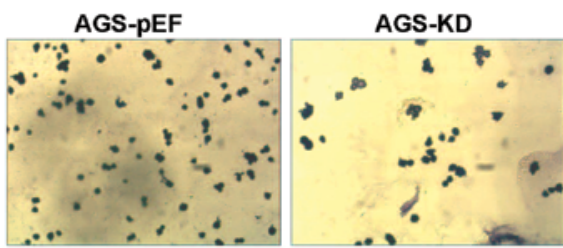

AGS SGPP1 adhesion assay

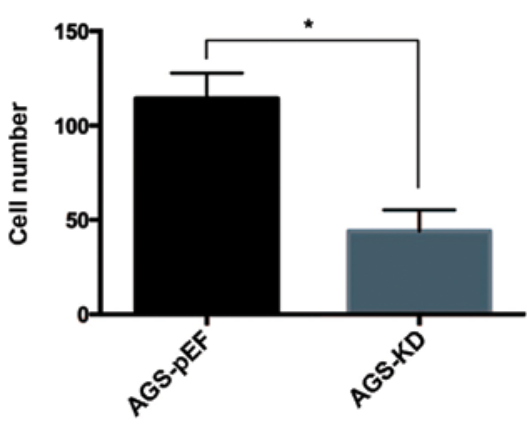

AGS SGPP1 growth assay

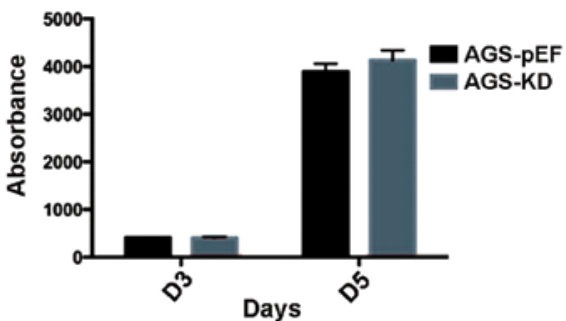

Figure 4. (A) In vitro adhesion test in AGS and HGC27 cell lines. Both HGC27 SGPP1 KD cell (left panel) and AGS KD cell (right panel) showed less adhesion ability compared with the control cell lines. (B) In vitro growth test in AGS and HGC27 cell lines; HGC27 SGPP1 KD cell grew slower than the corresponding control cell lines on day 5 (left panel), although no significant difference in AGS knockdown cell was observed (left panel). Experiments were repeated at least three times. Data are represented as mean \pm SEM; ${ }^{*}<<0.05$. SGPP1, sphingosine-1-phosphate phosphatase 1; KD, knockdown.

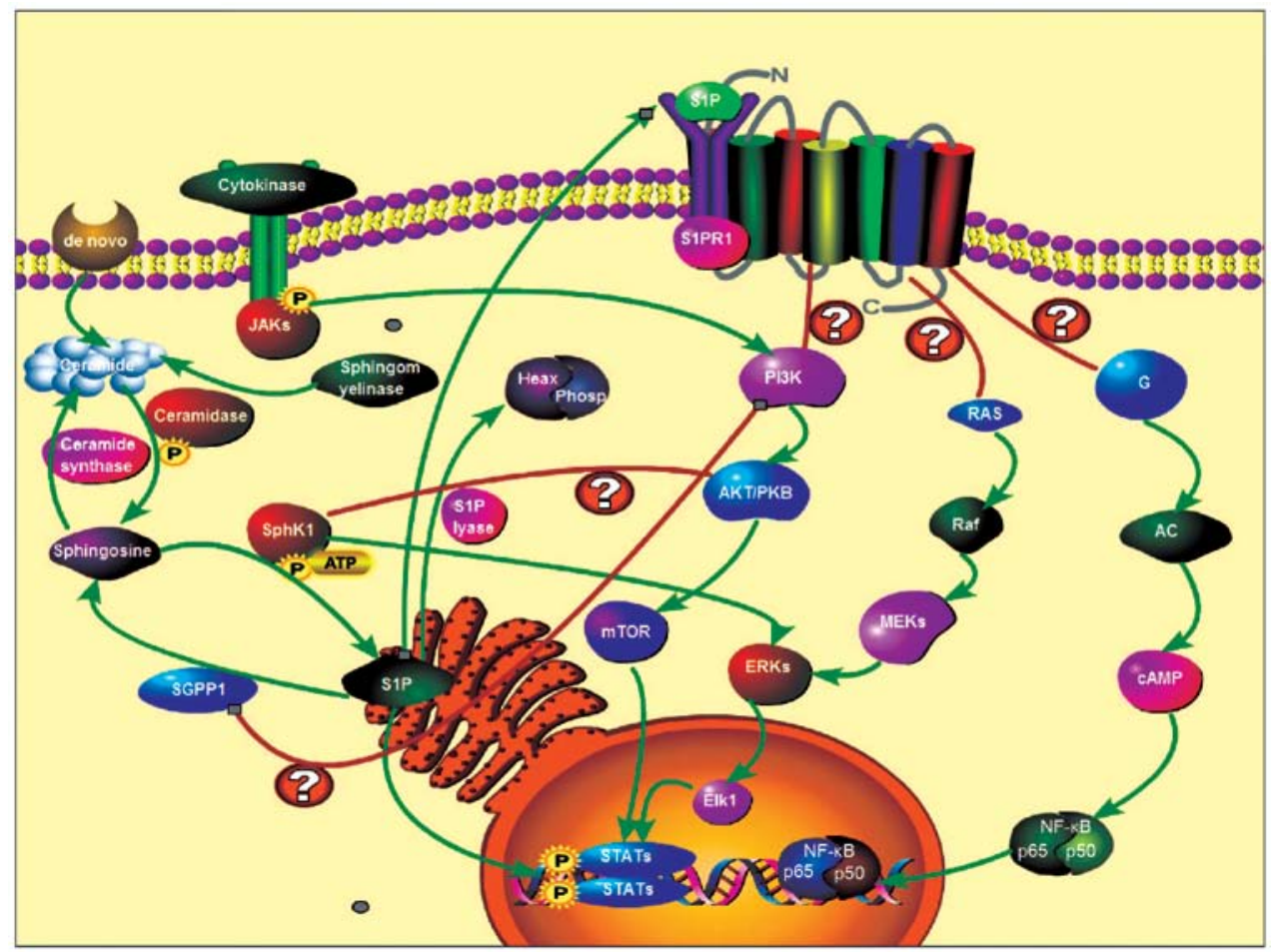

Figure 5. Diagram depicting S1P signaling pathway. S1P, sphingosine-1-phosphate. 
novel molecular prognosticator in the evaluation of gastric cancer patient survival.

Invasion and metastasis are major obstacles in the effort to improve survival of gastric cancer patients (37). Our in vitro study showed that the cell ability of invasion and migration was markedly increased in the gastric cell lines which the expression of SGPPl is downregulated compared with the negative control. This phenomenon is similar to the observation in the data, showing a significant association with lymph node metastasis. Collectively, we suggest that SGPPI serves as a novel prognostic marker of cancer cell invasion and metastasis. In addition, we found that downregulating the expression of SGPPl affected the adhesion and growth ability in HGC27 cells but no significant change occurred in AGS cells. The reason for this phenomenon may be that the cancer cell decreases the ability of adhesion from the primary location and at the same time increases the ability of invasion and metastasis and epithelial-mesenchymal transition

In conclusion, the result show that SGPPI expression is significantly lower in tumor tissue than that in the normal paired tissue, while downregulation of SGPPl leads to an increase in cell migration and invasion in gastric cancer. A lower $S G P P 1$ expression is correlated with lymph node metastasis and SGPPI expression knockdown may lead to a more aggressive invasion and migration ability. Therefore, there is a significant correlation between SGPPl expression and OS, PFS in the gastric cancer cohort. Taken together, the results indicate $S G P P 1$ is a potential molecular marker that may be used to predict the effectiveness of prognosis in gastric cancer patients.

\section{Acknowledgements}

The authors wish to thank Cancer Research Wales, the Albert Hung Foundation, the Yiling Foundation, the Ser Cymru Welsh Life Science Network, Beijing Municipal Science \& Technology Commission (D141100000414002) and the Natural Science Foundation of China (81374016) for supporting their work. Dr Xiang Y. Gao is a recipient of Cardiff University China Medical Scholarship.

\section{References}

1. Jemal A, Bray F, Center MM, Ferlay J, Ward E and Forman D: Global cancer statistics. CA Cancer J Clin 61: 69-90, 2011.

2. Cunningham D and Chua YJ: East meets west in the treatment of gastric cancer. N Engl J Med 357: 1863-1865, 2007.

3. Petrelli NJ: The debate is over; it's time to move on. J Clin Oncol 22: 2041-2042, 2004.

4. Cunningham D, Allum WH, Stenning SP, Thompson JN, Van de Velde CJ, Nicolson M, Scarffe JH, Lofts FJ, Falk SJ, Iveson TJ, et al; MAGIC Trial Participants: Perioperative chemotherapy versus surgery alone for resectable gastroesophageal cancer. N Engl J Med 355: 11-20, 2006.

5. Bang YJ, Van Cutsem E, Feyereislova A, Chung HC, Shen L, Sawaki A,Lordick F, Ohtsu A, Omuro Y, Satoh T, et al; ToGA Tria Investigators: Trastuzumab in combination with chemotherapy versus chemotherapy alone for treatment of HER2-positive advanced gastric or gastro-oesophageal junction cancer (ToGA) A phase 3, open-label, randomised controlled trial. Lancet 376: 687-697, 2010

6. Van Cutsem E, de Haas S, Kang YK, Ohtsu A, Tebbutt NC, Ming Xu J, Peng Yong W, Langer B, Delmar P, Scherer SJ, et al: Bevacizumab in combination with chemotherapy as first-line therapy in advanced gastric cancer: A biomarker evaluation from the AVAGAST randomized phase III trial. J Clin Oncol 30 2119-2127, 2012.
7. Payne SG, Milstien S and Spiegel S: Sphingosine-1-phosphate: Dual messenger functions. FEBS Lett 531: 54-57, 2002.

8. Johnson KR, Johnson KY, Becker KP, Bielawski J, Mao C and Obeid LM: Role of human sphingosine-1-phosphate phosphatase 1 in the regulation of intra- and extracellular sphingosine-1-phosphate levels and cell viability. J Biol Chem 278: 34541-34547, 2003.

9. Le Stunff H, Galve-Roperh I, Peterson C, Milstien S and Spiegel S: Sphingosine-1-phosphate phosphohydrolase in regulation of sphingolipid metabolism and apoptosis. J Cell Biol 158: 1039-1049, 2002

10. Huang X, Taeb S, Jahangiri S, Emmenegger U, Tran E, Bruce J, Mesci A, Korpela E, Vesprini D, Wong CS, et al: miRNA-95 mediates radioresistance in tumors by targeting the sphingolipid phosphatase SGPP1. Cancer Res 73: 6972-6986, 2013.

11. Ji K, Ye L, Toms AM, Hargest R, Martin TA, Ruge F, Ji J and Jiang WG: Expression of signal-induced proliferation-associated gene 1 (SIPA1), a RapGTPase-activating protein, is increased in colorectal cancer and has diverse effects on functions of colorectal cancer cells. Cancer Genomics Proteomics 9: 321-327, 2012.

12. Jiang WG, Grimshaw D, Lane J, Martin TA, Abounader R, Laterra J and Mansel RE: A hammerhead ribozyme suppresses expression of hepatocyte growth factor/scatter factor receptor c-MET and reduces migration and invasiveness of breast cancer cells. Clin Cancer Res 7: 2555-2562, 2001.

13. Parr C and Jiang WG: Metastasis suppressor 1 (MTSS1) demonstrates prognostic value and anti-metastatic properties in breast cancer. Eur J Cancer 45: 1673-1683, 2009.

14. Jiang WG, Hiscox S, Hallett MB, Scott C, Horrobin DF and Puntis MC: Inhibition of hepatocyte growth factor-induced motility and in vitro invasion of human colon cancer cells by gamma-linolenic acid. Br J Cancer 71: 744-752, 1995.

15. Jiang WG, Hiscox SE, Parr C, Martin TA, Matsumoto K, Nakamura T and Mansel RE: Antagonistic effect of NK4, a novel hepatocyte growth factor variant, on in vitro angiogenesis of human vascular endothelial cells. Clin Cancer Res 5: 3695-3703, 1999.

16. Bertuccio P, Chatenoud L, Levi F, Praud D, Ferlay J, Negri E, Malvezzi M and La Vecchia C: Recent patterns in gastric cancer: A global overview. Int J Cancer 125: 666-673, 2009.

17. Rivera F, Vega-Villegas ME and López-Brea MF: Chemotherapy of advanced gastric cancer. Cancer Treat Rev 33: 315-324, 2007.

18. Sasako M, Sakuramoto S, Katai H, Kinoshita T, Furukawa H, Yamaguchi T, Nashimoto A, Fujii M, Nakajima T and Ohashi Y: Five-year outcomes of a randomized phase III trial comparing adjuvant chemotherapy with S-1 versus surgery alone in stage II or III gastric cancer. J Clin Oncol 29: 4387-4393, 2011.

19. Lee J, Lim H, Kim S, Park SH, Park JO, Park YS, Lim HY, Choi MG, Sohn TS, Noh JH, et al: Phase III trial comparing capecitabine plus cisplatin versus capecitabine plus cisplatin with concurrent capecitabine radiotherapy in completely resected gastric cancer with D2 lymph node dissection: The ARTIST trial. J Clin Oncol 30: 268-273, 2012.

20. Falcone A: Future strategies and adjuvant treatment of gastric cancer. Ann Oncol 14 (Suppl 2): ii45-47, 2003.

21. Hannun YA: Functions of ceramide in coordinating cellular responses to stress. Science 274: 1855-1859, 1996.

22. Boujaoude LC, Bradshaw-Wilder C, Mao C, Cohn J, Ogretmen B, Hannun YA and Obeid LM: Cystic fibrosis transmembrane regulator regulates uptake of sphingoid base phosphates and lysophosphatidic acid: Modulation of cellular activity of sphingosine 1-phosphate. J Biol Chem 276: 35258-35264, 2001.

23. Hannun YA and Obeid LM: Principles of bioactive lipid signalling: Lessons from sphingolipids. Nat Rev Mol Cell Biol 9: 139-150, 2008.

24. Wojciak JM, Zhu N, Schuerenberg KT, Moreno K, Shestowsky WS, Hiraiwa M, Sabbadini R and Huxford T: The crystal structure of sphingosine-1-phosphate in complex with a Fab fragment reveals metal bridging of an antibody and its antigen. Proc Natl Acad Sci USA 106: 17717-17722, 2009.

25. Hla T, Lee MJ, Ancellin N, Paik JH and Kluk MJ: Lysophospholipids - receptor revelations. Science 294: 1875-1878, 2001.

26. Anliker B and Chun J: Lysophospholipid G protein-coupled receptors. J Biol Chem 279: 20555-20558, 2004.

27. Strub GM, Paillard M, Liang J, Gomez L, Allegood JC, Hait NC, Maceyka M, Price MM, Chen Q, Simpson DC, et al: Sphingosine-1-phosphate produced by sphingosine kinase 2 in mitochondria interacts with prohibitin 2 to regulate complex IV assembly and respiration. FASEB J 25: 600-612, 2011. 
28. Alvarez SE, Harikumar KB, Hait NC, Allegood J, Strub GM, Kim EY, Maceyka M, Jiang H, Luo C, Kordula T, et al: Sphingosine-1-phosphate is a missing cofactor for the E3 ubiquitin ligase TRAF2. Nature 465: 1084-1088, 2010.

29. Hait NC, Allegood J, Maceyka M, Strub GM, Harikumar KB, Singh SK, Luo C, Marmorstein R, Kordula T, Milstien S, et al: Regulation of histone acetylation in the nucleus by sphingosine-1-phosphate. Science 325: 1254-1257, 2009.

30. Xia P and Wadham C: Sphingosine 1-phosphate, a key mediator of the cytokine network: Juxtacrine signaling. Cytokine Growth Factor Rev 22: 45-53, 2011.

31. Mandala SM, Thornton R, Galve-Roperh I, Poulton S, Peterson C, Olivera A, Bergstrom J, Kurtz MB and Spiegel S: Molecular cloning and characterization of a lipid phosphohydrolase that degrades sphingosine-1- phosphate and induces cell death. Proc Natl Acad Sci USA 97: 7859-7864, 2000.

32. Ogawa C, Kihara A, Gokoh M and Igarashi Y: Identification and characterization of a novel human sphingosine-1-phosphate phosphohydrolase, hSPP2. J Biol Chem 278: 1268-1272, 2003.
33. Mandala SM: Sphingosine-1-phosphate phosphatases. Prostaglandins 64: 143-156, 2001.

34. Venkataraman K, Lee YM, Michaud J, Thangada S, Ai Y, Bonkovsky HL, Parikh NS, Habrukowich C and Hla T: Vascular endothelium as a contributor of plasma sphingosine 1-phosphate. Circ Res 102: 669-676, 2008.

35. Lépine S, Allegood JC, Park M, Dent P, Milstien S and Spiegel S: Sphingosine-1-phosphate phosphohydrolase-1 regulates ER stress-induced autophagy. Cell Death Differ 18: 350-361, 2011.

36. Peter BF, Lidington D, Harada A, Bolz HJ, Vogel L, Heximer S, Spiegel S, Pohl U and Bolz SS: Role of sphingosine-1-phosphate phosphohydrolase 1 in the regulation of resistance artery tone. Circ Res 103: 315-324, 2008.

37. Cervantes A, Roselló S, Roda D and Rodríguez-Braun E: The treatment of advanced gastric cancer: Current strategies and future perspectives. Ann Oncol 19 (Suppl 5): v103-v107, 2008. 